\title{
Kinematic Analysis of a Clamp-Type Picking Device for an Automatic Pepper Transplanter
}

\author{
Md Nafiul Islam ${ }^{1}\left(\mathbb{D}\right.$, Md Zafar Iqbal $^{2} \mathbb{C}^{-}$, Mohammod Ali ${ }^{1}$, Milon Chowdhury ${ }^{1,3}{ }^{10}$, \\ Md Shaha Nur Kabir ${ }^{4}$, Tusan Park ${ }^{5,6} \mathbb{D}$, Yong-Joo Kim ${ }^{1,3}(\mathbb{D}$ and Sun-Ok Chung 1,3,*(D) \\ 1 Department of Agricultural Machinery Engineering, Graduate School, Chungnam National University, \\ Daejeon 34134, Korea; nafiulislam@cnu.ac.kr (M.N.I.); sdali77@o.cnu.ac.kr (M.A.); \\ chowdhurym90@cnu.ac.kr (M.C.); babina@cnu.ac.kr (Y.-J.K.) \\ 2 Department of Biological and Agricultural Engineering, College of Agriculture and Life Sciences, \\ Texas A\&M University, College Station, TX 77843, USA; z_iqbal@tamu.edu \\ 3 Department of Smart Agricultural Systems, Graduate School, Chungnam National University, \\ Daejeon 34134, Korea \\ 4 Department of Agricultural and Industrial Engineering, Faculty of Engineering, \\ Hajee Mohammad Danesh Science and Technology University, Dinajpur 5200, Bangladesh; \\ kabir1982@hstu.ac.bd \\ 5 Department of Bio-Industrial Machinery Engineering, College of Agriculture and Life Sciences, \\ Kyungpook National University, Daegu 41566, Korea; tusan.park@knu.ac.kr \\ 6 Smart Agriculture Innovation Center, Kyungpook National University, Daegu 41566, Korea \\ * Correspondence: sochung@cnu.ac.kr; Tel.: +82-42-821-6712; Fax: +82-42-823-6246
}

Received: 1 November 2020; Accepted: 10 December 2020; Published: 12 December 2020

\begin{abstract}
Pepper is one of the most vital agricultural products with high economic value, and pepper production needs to satisfy the growing worldwide population by introducing automatic seedling transplantation techniques. Optimal design and dimensioning of picking device components for an automatic pepper transplanter are crucial for efficient and effective seedling transplantation. Therefore, kinematic analysis, virtual model simulation, and validation testing of a prototype were conducted to propose a best-suited dimension for a clamp-type picking device. The proposed picking device mainly consisted of a manipulator with five grippers and a picking stand. To analyze the influence of design variables through kinematic analysis, 250- to 500-mm length combinations were considered to meet the trajectory requirements and suit the picking workspace. Virtual model simulation and high-speed photography tests were conducted to obtain the kinematic characteristics of the picking device. According to the kinematic analysis, a 350-mm picking stand and a 380-mm manipulator were selected within the range of the considered combinations. The maximum velocity and acceleration of the grippers were recorded as $1.1,2.2 \mathrm{~m} / \mathrm{s}$ and $1.3,23.7 \mathrm{~m} / \mathrm{s}^{2}$, along the $x$ - and $y$-axes, respectively, for 30 to $90 \mathrm{rpm}$ operating conditions. A suitable picking device dimension was identified and validated based on the suitability of the picking device working trajectory, velocity, and acceleration of the grippers, and no significant difference $(p \leq 0.05)$ occurred between the simulation and validation tests. This study indicated that the picking device under development would increase the pepper seedling picking accuracy and motion safety by reducing the operational time, gripper velocity, acceleration, and mechanical damage.
\end{abstract}

Keywords: agricultural machinery; pepper; transplanter; picking device; kinematic analysis

\section{Introduction}

Pepper (Capsicum annuum L.) is one of the most consumed vegetables and a significant source of vitamins such as vitamin C, E, A, and B complex [1]; it is also the second most exported vegetable 
worldwide [2,3]. In 2018, the global pepper production was 36,771 thousand tons from an area of 1990 thousand ha, with the production increasing from 8656 thousand tons $(23.5 \%)$ and cultivation area of 179 thousand ha (9\%) since 2008 [4]. Some tropical and subtropical regions, including India, Indonesia, Malaysia, Thailand, Brazil, Sri Lanka, Vietnam, and China, are the leading pepper cultivation zones [5]. Although the pepper cultivation rate and cultivated area are increasing worldwide, a decrease in pepper production has been recorded in some countries (e.g., the Republic of Korea and Japan) over the last few years due to the lack of mechanization, farm labor shortage, small scale of agricultural land, and aging of the farmers [6-8]. Therefore, these countries need to adopt suitable automated techniques to overcome pepper cultivation difficulties.

In recent years, mechanized vegetable transplanting techniques have become popular for efficient seedling transplantation to reduce the production cost and transplantation time $[9,10]$. In manual transplanting, the spatial distribution of seedlings is often non-uniform owing to human error [11,12]. Subsequently, semi-automated transplanters are placed in a manual transplanter to transplant the seedlings more uniformly. However, it requires one farmer to control the transplanter movement and other farmers to feed the seedlings into the transplanting mechanism [13]. In addition to the semi-automatic technique, several researchers have focused on updating automatic and robotic vegetable transplanters containing a seedling transfer unit (picking device) to minimize extra laborers [13-17]. The performance of the automatic transplanter depends mainly on the success rate of picking the seedlings from the tray and dibbling them into the soil. Therefore, the picking device is a crucial part of the automatic type transplanter; it reduces operational drudgery by carrying out the task repetitively in a precise and consistent manner.

Research and development of picking devices in agriculture started in the 1980s [18]. In the first stage, to create bedding plants inside a greenhouse, researchers have developed several types of seedling picking devices to transfer seedlings from high-concentration to low-concentration trays [19-21]. They mainly focused on control engineering technologies such as machine vision and sensing. Since the 2000s, new generation seedling picking devices have been developed to transfer seedlings with different types of mechanisms. These types of devices simultaneously drive the seedlings horizontally $(x$-axis) and vertically (y-axis) [22,23]. Based on the principle of the picking devices used in greenhouses, researchers were motivated to develop an automatic transplanter for upland crops, especially rice and corn seedling transplantation [24-27]. A seedling picking device for vegetables was developed with a five-bar mechanism (fixed, driving, driven, connecting, and slider link) for seedling extraction [23]. Researchers have reported a robotic transplanter with a picking device to move the seedlings to the desired working position. The robotic transplanter's picking device consisted of a manipulator, a gripper, plug tray conveyors, and a vision system. Some laboratory seedling picking devices were examined, where the seedlings were transferred to the horizontal and vertical paths [28,29]. A single-type gripper is used for the picking operation, and higher velocity and acceleration are required for speedy motion.

Excessive velocity and acceleration may damage the seedlings or interrupt the picking process. Instead of a single-type gripper, multiple grippers would reduce the operational time; it may also execute a secure and stable pick-and-place operation by minimizing the velocity and acceleration range. Researchers also investigated several types of grippers and analyzed the accuracy; among them, the clamp-type [19] and sliding-type [20,21] were the most useful gripping methods for mechanical seedling transplantation. The two types of grippers target the midpoint of the root of the seedlings. The sliding-type gripper can easily hold the seedlings; however, this method has some complications for discharging seedlings. In this method, seedling roots sometimes stick to the grippers, and picking failure can occur. By contrast, clamp-type grippers may release the seedlings accurately by exploiting the seedling motion; however, owing to the short needle, this method also faces some difficulties in holding the seedlings [30]. In this regard, a long needle clamp-type gripper may solve the problem of holding and releasing the seedlings safely. 
In this study, a new type of long needle multiple clamp-type gripper picking device was proposed for automatic pepper seedling transplantation. To optimize and suggest the best-suited dimensions for the introduced picking device, kinematic modeling and analysis, simulation, and field tests were necessary. Therefore, the objectives of this study were (i) to develop kinematic modeling to suggest a best-suited picking device dimension by analyzing the effects of the kinematic characteristics (i.e., position, velocity, and acceleration) of the gripper, and (ii) to set up a virtual simulation environment and a field test of the prototype for validating the gripper trajectory planning, velocity, and acceleration requirements.

\section{Materials and Methods}

\subsection{Structure of Transplanter and Working Principle of the Picking Device}

The overall structure of the under development automatic pepper transplanter with a picking mechanism is shown in Figure 1. The transplanter consisted of a clamp-type picking device, conveying device, and two-row planting device. The purpose of the seedling picking device was to automatically collect seedlings from the seedling tray and transfer them into the planting device by minimizing the mechanical or operational damage [30]. For mechanical transplanting operations, seedlings are generally grown in paper pots in a plastic tray before transplanting them into the soil [31]. The 45-day-old paper pot seedlings $(\varnothing 40 \times 40 \mathrm{~mm})$ are relatively convenient for mechanical transplantation in terms of sustainability and growth [32].

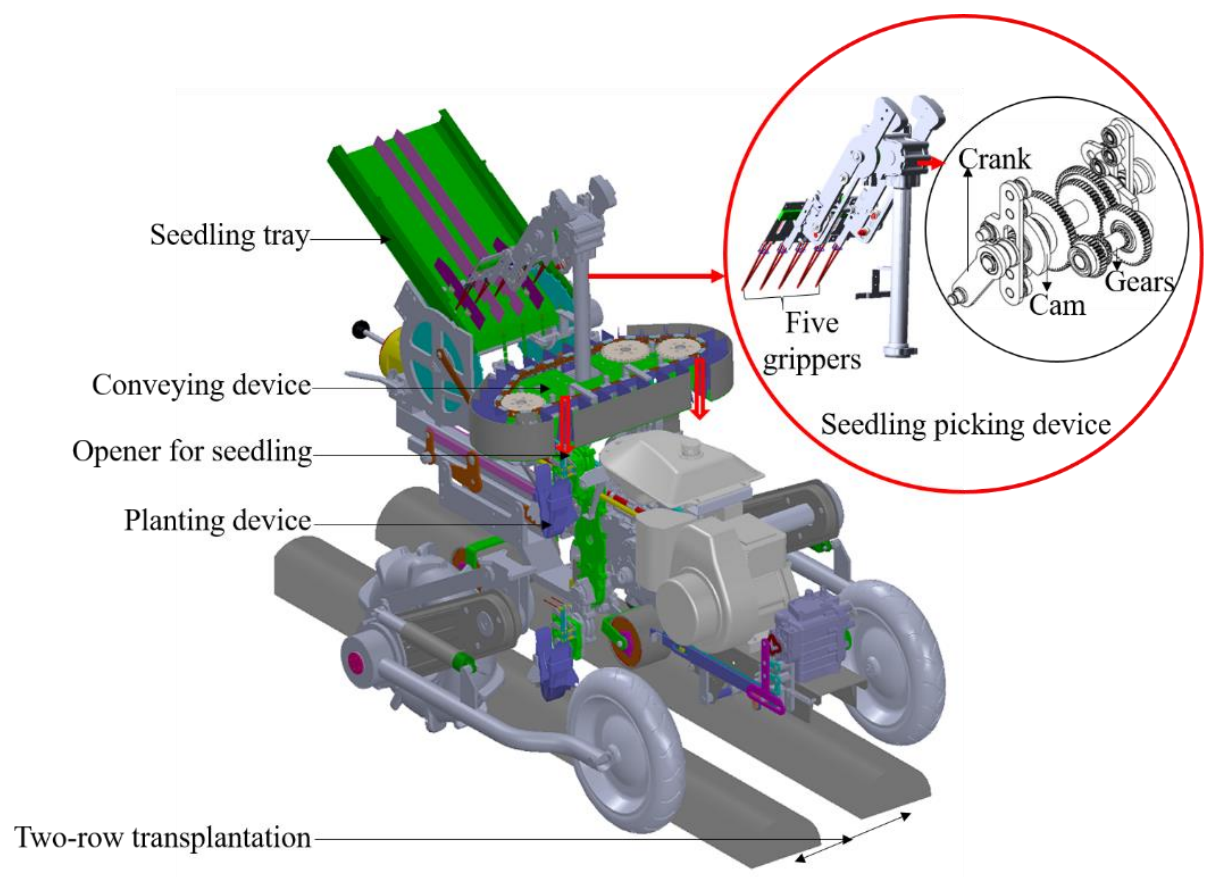

Figure 1. Overall structure of the automatic pepper seedling transplanter under development.

The picking device comprised a manipulator and five grippers. The grippers were attached by a revolute joint to the upper platform of the manipulator. Previously, researchers used 60-75-mm range needles for pick-and-place operations [22-25]. In this research, the clamp-type grippers were revised to ensure the stabilizing strength and used $120 \mathrm{~mm}$ needles to release the seedlings. The manipulator was used to move the grippers to the conveying device with a cam-crank mechanism. The cranks derived the grippers in the $y$-axis and the cams in the $x$-axis. Two types of spur gear trains were attached to the gear shaft: a 1:1 gear ratio for the crank and 2:1 gear ratio for the cam. Therefore, the rotational speed of the cam-driven gear was half that of the crank-driven gears. After completing one cycle of operation, the picking device dropped five seedlings on the conveying device and returned towards 
the seedling tray during the opposite movement. The automatic pepper seedling transplanter was designed for transplanting the seedlings in a two-row pattern. The conveying device transferred the seedlings based on the demand of the planting device. The conveying unit has two seedling openers and drops the seedlings into the two-row planting device using them.

The working space of the picking device was determined by the distance between the seedling tray and the picking stand. The consideration of the gripper and manipulator design is a comprehensive task because it can minimize the seedling motion and make a convenient picking operation. In this mechanism, an explanation is required for trajectory planning to solve the position of the gripper pick-and-place operation and the velocity acceleration in the case of the known position of the moving manipulator. Kinematic analysis involves expressing the equations of motion and solving them for the position, velocity, and acceleration of the system components [33,34]. This analysis is necessary for design optimization, particularly for the picking workspace analysis, where kinematic parameters (i.e., position, velocity, and acceleration) of the moving bars must be known to assess the mechanical system performance and functionality.

\subsection{Kinematic Analysis of the Picking Device Grippers}

Grippers picked the seedlings from the seedling tray (point A) and moved the $y$-axis to point $B$ (Figure 2a). The cam mechanism moved the grippers from point $B$ to $C$ to release the seedlings. After releasing the seedlings, the crank mechanism assisted the grippers to move to point $\mathrm{D}$ by the $y$-axis movement. Finally, the grippers returned to position A and completed the one-cycle picking operation with a single degree of freedom. The seedling tray was continuously moved downward, and five grippers picked five seedlings from the tray. The azimuth angle of the seedling pick-up was $90^{\circ}$. The angle of the seedling tray was designed to be kept at $80^{\circ}$ to $100^{\circ}$. If this angle is less than $80^{\circ}$, then the required power of seedling transfer will be increased, or the angle is more than $100^{\circ}$, there is a higher possibility of breaking or falling the seedlings [32,35].

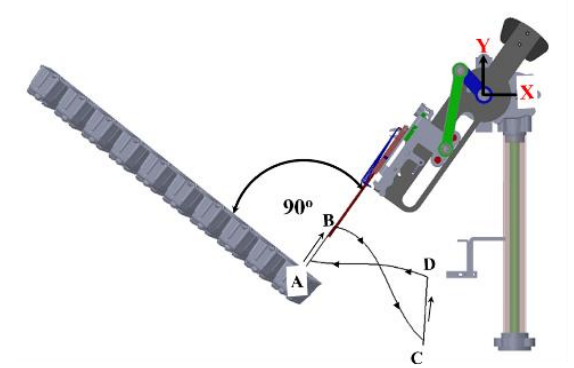

(a)

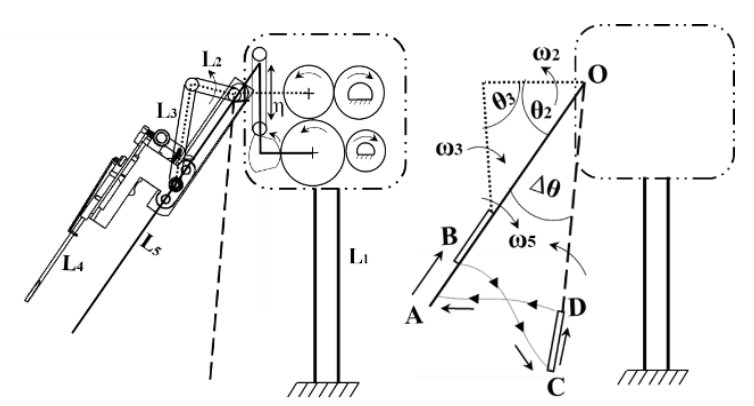

(b)

Figure 2. Schematic diagram of the picking device: (a) azimuth angle of the trajectory; (b) kinematic model for the picking device: $\left(L_{1}\right)$ picking stand, $\left(L_{2}\right)$ crank, $\left(L_{3}\right)$ connecting rod, $\left(L_{4}\right)$ gripper, $\left(L_{5}\right)$ manipulator, (A-B-C-D-A) trajectory path.

The picking device working space depends on the height of the picking stand and the distance from the seedling tray. A gearbox was located on the picking stand, which assisted the cam and crank rotation. The crank and camshaft are continuously rotated by $360^{\circ}$ to pick the seedling in the tray and drop it to the conveying device. According to Figure $2 b, L_{1}$ is the picking stand and acts as a fixed bar, and $L_{2}, L_{3}, L_{4}$, and $L_{5}$ are moving bars. A vector-loop model was used to define the kinematic parameters (position, velocity, and acceleration) of the gripper by solving the angles of the moving bars in the case of the known position of the fixed bar. Table 1 indicates the variable notations, definitions, and measurement units are used in this analysis. 
Table 1. Variable notations, definitions, and measurement units.

\begin{tabular}{|c|c|}
\hline Notation & Definitions and Measurement Units \\
\hline$\eta$ & Maximum distance between the cam follower and slider, $\mathrm{mm}$ \\
\hline $\mathrm{b}$ & Distance between the picking stand and seedling tray, mm \\
\hline$L_{5}$ & Picking stand length, $\mathrm{mm}$ \\
\hline$L_{2}$ & Crank length, $\mathrm{mm}$ \\
\hline$L_{3}$ & Connecting rod length, $\mathrm{mm}$ \\
\hline$L_{4}$ & Gripper length, $\mathrm{mm}$ \\
\hline$e$ & Euler's formula base of the natural logarithm \\
\hline$i$ & Imaginary unit \\
\hline$\theta_{2}$ & Crank angle, radians \\
\hline$\theta_{3}$ & Connecting rod angle, radians \\
\hline$\theta_{4}$ & Gripper angle, radians \\
\hline$\Delta \theta$ & Cam rotational angle, radians \\
\hline$X_{A_{1}}$ & Gripper $x$-axis coordinates \\
\hline$Y_{A_{1}}$ & Gripper $y$-axis coordinates \\
\hline$\dot{L_{2}}$ & Crank velocity, mm/s (convert to $\mathrm{m} / \mathrm{s}$ ) \\
\hline$\dot{L_{3}}$ & Connecting rod velocity, mm/s (convert to m/s) \\
\hline$\dot{L_{4}}$ & Gripper $y$-axis velocity, mm/s (convert to m/s) \\
\hline$\omega_{2}$ & Crank angular velocity, $\mathrm{rad} / \mathrm{s}$ \\
\hline$\omega_{3}$ & Connecting rod angular velocity, $\mathrm{rad} / \mathrm{s}$ \\
\hline$V_{O A}$ & Gripper $x$-axis velocity, $\mathrm{mm} / \mathrm{s}$ (convert to $\mathrm{m} / \mathrm{s}$ ) \\
\hline$\ddot{L_{2}}$ & Crank acceleration, $\mathrm{mm} / \mathrm{s}^{2}\left(\right.$ convert to $\mathrm{m} / \mathrm{s}^{2}$ ) \\
\hline$\ddot{L_{3}}$ & Connecting rod acceleration, $\mathrm{mm} / \mathrm{s}^{2}$ (convert to $\mathrm{m} / \mathrm{s}^{2}$ ) \\
\hline$\ddot{L_{4}}$ & Gripper $y$-axis acceleration, $\mathrm{mm} / \mathrm{s}^{2}$ (convert to $\mathrm{m} / \mathrm{s}^{2}$ ) \\
\hline$\alpha_{2}$ & Crank angular acceleration, $\mathrm{rad} / \mathrm{s}^{2}$ \\
\hline$\alpha_{3}$ & Connecting rod angular acceleration, $\mathrm{rad} / \mathrm{s}^{2}$ \\
\hline$\alpha$ & Gripper $x$-axis acceleration, $\mathrm{mm} / \mathrm{s}^{2}\left(\right.$ convert to $\left.\mathrm{m} / \mathrm{s}^{2}\right)$ \\
\hline
\end{tabular}

\subsubsection{Variables of Picking Device for Optimization of the Design}

The relation between the working space and the dimension of the picking device could be demonstrated by the reflecting factor $(\delta)$. If the reflecting factor of the picking device is too small, the distance between the picking stand and seedling tray would be larger than the length of the picking stand. By contrast, if $\delta$ is too large, the operating performance will eventually decline [29]. The relation between the device dimension and reflecting factor can be described by Equation (1).

$$
1 \leq \delta=\frac{b}{2\left(\eta+L_{5}\right)} \leq \delta_{\max }
$$

The angle (azimuth) for the seedling tray was considered to be the main factor in a successful pick-and-place operation [32]. For kinematic analysis, the length of the picking stand and manipulator were considered to be in the $250-$ to $500-\mathrm{mm}$ range at $5-\mathrm{mm}$ intervals because in this range, the $90^{\circ}$ azimuth angle was ensured. In the 250- to 500-mm range and considering the reflecting factor, 13 combinations were selected to satisfy the working space requirements of this picking device (Table 2). 
Table 2. Selected feasible length combinations of picking stand and manipulation.

\begin{tabular}{cccc}
\hline Combination & Manipulator, $\mathbf{m m}$ & Picking Stand Length, mm & Manipulator Movement Angle $(\boldsymbol{\Delta} \boldsymbol{\theta}) \mathbf{,}^{\circ}$ \\
\hline 1 & 350 & 250 & 33.64 \\
2 & 350 & 300 & 36.29 \\
3 & 380 & 250 & 27.21 \\
4 & 380 & 300 & 28.46 \\
5 & 380 & 350 & 30.01 \\
6 & 410 & 250 & 26.92 \\
7 & 410 & 300 & 24.67 \\
8 & 410 & 350 & 24.89 \\
9 & 410 & 350 & 22.92 \\
10 & 440 & 300 & 23.56 \\
11 & 440 & 250 & 26.42 \\
12 & 440 & 400 & 25.62 \\
13 & 480 & 450 & 22.38 \\
\hline
\end{tabular}

\subsubsection{Position and Trajectory Evaluation of the Gripper with Vector-Loop Modeling}

The gripper position was controlled by different link operations such as rotation of the crank and connecting rod, and movement of the manipulator with respect to time. Figure 3 shows the timing profile of the device from pick to drop for seedling transfer. The circles 1,2, and 3 represent the cam profile, crank profile, and gear shaft, respectively.

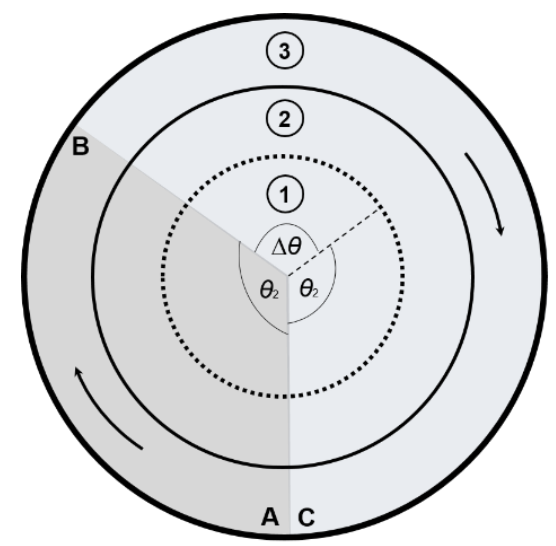

Figure 3. Timing profile of the device from seedlings pick to drop: $\left(\theta_{2}\right)$ crank rotational angle, $(\Delta \theta)$ cam rotational angel, (A) pick the seedlings, (B) change $y$-axis to $x$-axis, and (C) drop the seedlings.

The gripper position for the $y$-axis movement is controlled by a vector-loop model and a slider-crank mechanism with three bars $\left(L_{2}, L_{3}\right.$, and $\left.L_{4}\right)[36,37]$. The vector loop of the picking device can be expressed as Equation (2).

$$
L_{2} e^{i \theta_{2}}+L_{3} e^{i \theta_{3}}-L_{4} e^{i \theta_{4}}=0
$$

The gripper $\left(L_{4}\right)$ moves upward and downward. Because it is fully translated; $\theta_{4}=0$.

$$
L_{2} e^{i \theta_{2}}+L_{3} e^{i \theta_{3}}-L_{4}=0
$$

In the vector-loop equation, there is a real and imaginary part as shown below.

$$
L_{2}\left(\cos \theta_{2}+i \sin \theta_{2}\right)+L_{3}\left(\cos \theta_{3}+i \sin \theta_{3}\right)-L_{4}=0
$$

From Equation (4), the real and imaginary parts can be extracted as shown in Equations (5) and (6), respectively.

$$
L_{2} \cos \theta_{2}+L_{3} \cos \theta_{3}-L_{4}=0
$$




$$
L_{2} \sin \theta_{2}+L_{3} \sin \theta_{3}=0
$$

The position of the connecting rod and gripper is determined by calculating $\theta_{3}$ and $L_{4}$. The angle $\Delta \theta$ determines the position of $L_{5}$. The position of the required path of the $x$-axis can be determined by Equations (7) and (8).

$$
\begin{aligned}
& X_{A_{1}}=L_{5} \cos (\Delta \theta) \\
& Y_{A_{1}}=L_{5} \sin (\Delta \theta)
\end{aligned}
$$

2.2.3. Velocity of the Gripper with Vector-Loop Modeling

The gripper $y$-axis velocity can be found by taking the time derivative of Equation (2).

$$
\left(\dot{L_{2}}+i L_{2} \omega_{2}\right) e^{i \theta_{2}}+\left(\dot{L_{3}}+i L_{3} \omega_{3}\right) e^{i \theta_{3}}-\dot{L_{4}}=0
$$

In this mechanism, the $L_{2}$ and $L_{3}$ bars are fixed on one side; therefore, $\dot{L_{2}}=\dot{L_{3}}=0$.

$$
i L_{2} \omega_{2} e^{i \theta_{2}}+i L_{3} \omega_{3} e^{i \theta_{3}}-\dot{L_{4}}=0
$$

From Equation (10), the real and imaginary parts can be extracted as in Equations (11) and (12), respectively.

$$
\begin{gathered}
-L_{2} \omega_{2} \sin \theta_{2}-L_{3} \omega_{3} \sin \theta_{3}-\dot{L_{4}}=0 \\
L_{2} \omega_{2} \cos \theta_{2}+L_{3} \omega_{3} \cos \theta_{3}=0
\end{gathered}
$$

The gripper velocity is determined by calculating Equations (11) and (12). The gripper $x$-axis velocity could be determined by the position of the $L_{5}$ bar.

$$
V_{O A}=\frac{d \Delta \theta}{d t} \overrightarrow{L_{5}}
$$

\subsubsection{Acceleration of the Gripper with Vector-Loop Modeling}

The acceleration of the gripper $y$-axis movement can be determined by taking the time derivative of Equation (10).

$$
\left(\ddot{L_{2}}+i \dot{L_{2}} \omega_{2}+i L_{2} \alpha_{2}-L_{2} \omega_{2}^{2}\right) e^{i \theta_{2}}+\left(\ddot{L_{3}}+i \dot{L_{3}} \omega_{3}+i L_{3} \alpha_{3}-L_{2} \omega_{3}^{2}\right) e^{i \theta_{3}}-\ddot{L_{4}}=0
$$

In this mechanism, the $L_{2}$ and $L_{3}$ bars are fixed on one side; therefore, $\dot{L_{2}}=\dot{L_{3}}=\ddot{L_{2}}=\ddot{L_{3}}=0$. From Equations (15) and (16), the real and imaginary part yields,

$$
\begin{gathered}
-L_{2} \alpha_{2} \sin \theta_{2}-L_{2} \omega_{2}^{2} \cos \theta_{2}-L_{3} \alpha_{3} \sin \theta_{3}-L_{3} \omega_{3}^{2} \cos \theta_{3}-\ddot{L_{4}}=0 \\
L_{2} \alpha_{2} \cos \theta_{2}-L_{2} \omega_{2}^{2} \sin \theta_{2}-L_{3} \alpha_{3} \cos \theta_{3}-L_{3} \omega_{3}^{2} \sin \theta_{3}=0
\end{gathered}
$$

The connecting rod angular acceleration and gripper acceleration are found by calculating Equations (15) and (16). The gripper acceleration of the $x$-axis depends upon the point A. The gripper $x$-axis acceleration can be found by taking the time derivative of the Equation (13). Table 3 indicates the picking device components and describes the activity of each component to explain the vector-loop model.

$$
a=\left(\frac{d V}{d t} \times \overrightarrow{L_{5}}\right)+\left(\frac{d \theta}{d t} \times\left(\frac{d \theta}{d t} \times \overrightarrow{L_{5}}\right)\right)
$$


Table 3. Picking device components for vector-loop modeling.

\begin{tabular}{ccc}
\hline Component & Range & Activity \\
\hline Picking stand, $L_{1}$ & 250 to $500 \mathrm{~mm}$ & Determines the working space \\
Manipulator, $L_{5}$ & 250 to $500 \mathrm{~mm}$ & Moves the grippers \\
Crank, $L_{2}$ & Depend on $L_{5}$ & Moves the seedling in the $y$-axis \\
Connecting rod, $L_{3}$ & Depend on $L_{5}$ & Moves the seedling in the $y$-axis \\
Gripper, $L_{4}$ & Depend on $L_{5}$ & Pick or drop the seedling \\
Cam and follower, e & $25.5 \mathrm{~mm}$ & Moves the seedling in the $x$-axis \\
Gear and gear shaft & 30 to $90 \mathrm{rpm}$ & Run the cam and crank \\
\hline
\end{tabular}

\subsubsection{Simulation with Virtual Model}

The three-dimensional model was constructed for this investigation using a commercial computer-aided design software (SOLIDWORKS, Dassault Systemes SolidWorks Corp., Waltham, MA, USA). The software was used to evaluate the effects of gripper kinematic characteristics (position, velocity, and acceleration). The simulation could validate the vector-loop analysis result, design of the mechanism, and the trajectory that meets the seedling transfer requirements. The simulation assumed that the cover and other parts of the picking device made of the cast alloy steel and gear set made of the SCM $420 \mathrm{H}$ carbon steel.

\subsubsection{Experiment with a Prototype}

In order to validate the results from the kinematic analysis, a picking device prototype was fabricated and tested to determine the effect of the position of the working trajectory, velocity, and acceleration. A test bench was fabricated to run the prototype with a bevel gear transmission system. The picking device was synchronized with the motor driveline so that the motor could operate the picking device at the desired operating speed. A chain transmission system was also synchronized with the motor and driveline. A three-phase electric motor was used to provide the power to operate the picking device under different operating conditions (gearbox speed). The rated power was $1.5 \mathrm{~kW}$, rated speed was $3500 \mathrm{rpm}$, and frequency was $60 \mathrm{~Hz}$. An inverter (SV-iG5A; LS Electric Co. Ltd., Anyang, Republic of Korea) with an on/off switch was configured to control the motor's speed. Its rated power is $1.5 \mathrm{~kW}$, and the rated voltage for the three-phase is $200 \mathrm{~V}$. In order to obtain a suitable design structure for this mechanism, the primary considerations and variables in the simulated and measured are illustrated in Table 4.

Table 4. Parameters of the picking device components to validate the kinematic analysis results.

\begin{tabular}{ccc}
\hline \multirow{2}{*}{ Component } & \multicolumn{2}{c}{ Parameter } \\
\cline { 2 - 3 } & Simulated & Measured \\
\hline Picking stand, $L_{1}$ & $250 \mathrm{~mm}$ & $250 \mathrm{~mm}$ \\
Manipulator, $L_{5}$ & $380 \mathrm{~mm}$ & $380 \mathrm{~mm}$ \\
Gear and gear shaft & $60 \mathrm{rpm}$ & $60 \mathrm{rpm}$ \\
\hline
\end{tabular}

In order to determine the power consumption of the picking operation, a torque sensor (TRS605; FUTEK Advanced Sensor Technology, Inc., Irvine, CA, USA) was installed in the power driveline between the motor and the picking device. A triaxial acceleration sensor (model: SEN041F; PCB Piezotronics, Inc., NY, USA) was employed at the end of the gripper to evaluate the acceleration and velocity. A data acquisition device (NI 6212; National Instruments Corp., Austin, TX, USA), and a software program (LabVIEW; National Instruments Corp., Austin, TX, USA) were used to acquire the sensor signal data. Figure 4 a shows the fabrication and instrument setup of the validation test bench with a prototype device for velocity, acceleration, and power measurement. The torque sensor data were smoothed by using the moving average method based on 20-point symmetric [38]. The noise of the acceleration sensor data was filtered by applying fast Fourier transform and inverse fast Fourier 
transform methods [39]. The velocity of the gripper was derived by integrating the acceleration sensor data with time. Simulated and measured data were statistically analyzed using analysis of variance according to Tukey's one-way comparisons $(p \leq 0.05)$. The velocity and acceleration data were averaged, and expressed as means and standard deviations to obtain the significant difference. For the measurement, the experiment was repeated five times, and the velocity, acceleration, and power requirement data were recorded separately for each experiment. A smartphone was also installed to record the slow-motion video (720 p HD at $240 \mathrm{fps}$ ) of the picking device motion for measuring the working trajectory $[39,40]$. The picking device trajectory was evaluated using the open-source tracking software Kinovea $[40,41]$ and compared with the simulation result. Figure $4 \mathrm{~b}$ shows the fabrication and instrument setup for the trajectory evaluation.

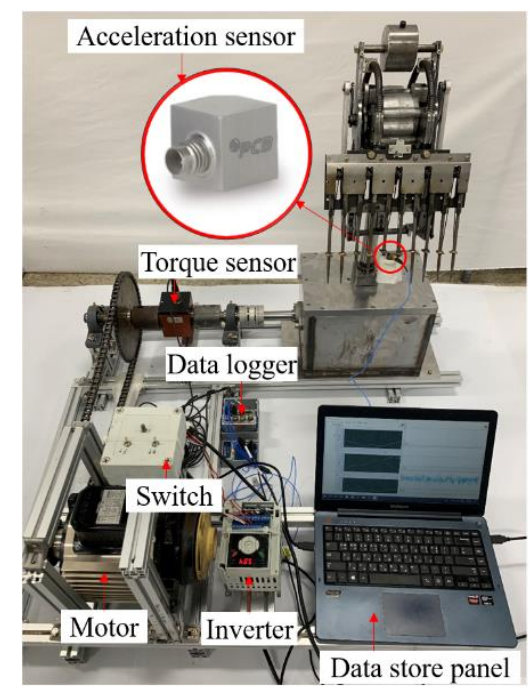

(a)

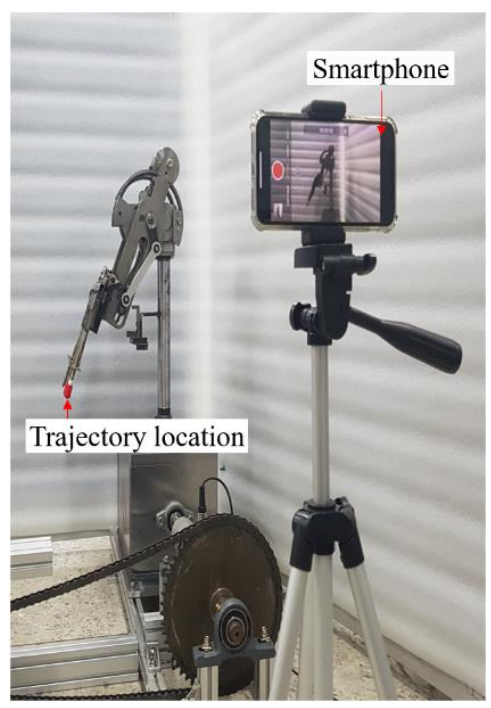

(b)

Figure 4. Validation test bench of the prototype picking device: (a) velocity, acceleration, and power measurement and (b) trajectory evaluation.

\section{Results and Discussion}

\subsection{Position and Trajectory of the Gripper}

Based on the position analysis, the gripper $y$-axis movement was controlled by the connecting rod ( $L_{3}$ bar), and the $x$-axis movement depended on the length of the picking stand $\left(L_{1}\right.$ bar). To enable the volume of the picking device for stable operation, the ratio (reflecting factor, $\delta$ ) between the picking working space and dimensions should be considered within a reasonable range. Therefore, it is recommended that $\delta=1.1$ to 1.2 [29]. The position analysis result shows that the 380-mm manipulator and the 250- to 350-mm range for the picking stand were acceptable combinations to maintain the recommended reflecting factor. The position analysis is based on the various dimensions (combination) used in Table 2, as presented in Table 5. 
Table 5. Position analysis results based on the various dimensions of the picking device bars.

\begin{tabular}{ccc}
\hline Combination & Gripper $\boldsymbol{y}$-Axis Movement, $\mathbf{m m}$ & Reflecting Factor, $\boldsymbol{\delta}$ \\
\hline 1 & 94.73 & 1.26 \\
2 & 80.44 & 1.26 \\
3 & 117.09 & 1.17 \\
4 & 117.68 & 1.17 \\
5 & 118.41 & 1.17 \\
6 & 140.79 & 1.08 \\
7 & 139.59 & 1.08 \\
8 & 139.71 & 1.08 \\
9 & 154.08 & 1.08 \\
10 & 154.45 & 1.01 \\
11 & 79.45 & 1.01 \\
12 & 155.64 & 1.01 \\
13 & 193.13 & 0.93 \\
\hline
\end{tabular}

Previous researchers such as Han et al. [42] found that the seedling $y$-axis movement of 70 to $140-\mathrm{mm}$ is suitable for extraction, and $\mathrm{Hu}$ et al. [29] fixed the $y$-axis movement of $120-\mathrm{mm}$ for a successful picking operation. The 380-mm manipulator and 250- to 350-mm picking stand only maintained the recommended operational height condition. Among them, 380-mm manipulator and 350-mm picking stand combination was maintained at the maximum recommended (118.41-mm) $y$-axis movement and selected for further analysis (simulated and measured).

The working trajectory of the picking mechanism extracted from the high-speed photography test provided a trajectory similar to the simulated one. This paper proposed a 'sickle' type trajectory curves to achieve high efficiency and low loss of seedling dropping [15]. The $y$-axis movement was found to be $118.41 \mathrm{~mm}$ for kinematic analysis. In the simulation and experimental analysis, the $y$-axis movement was 118.41-mm, and the pick (A) and drop (D) position were in the same coordinate, as shown in Figure 5. However, there was a small difference in the trajectory path compared to the simulation. The difference between the two trajectory paths may occur due to the additional vibration under working conditions $[39,43]$.

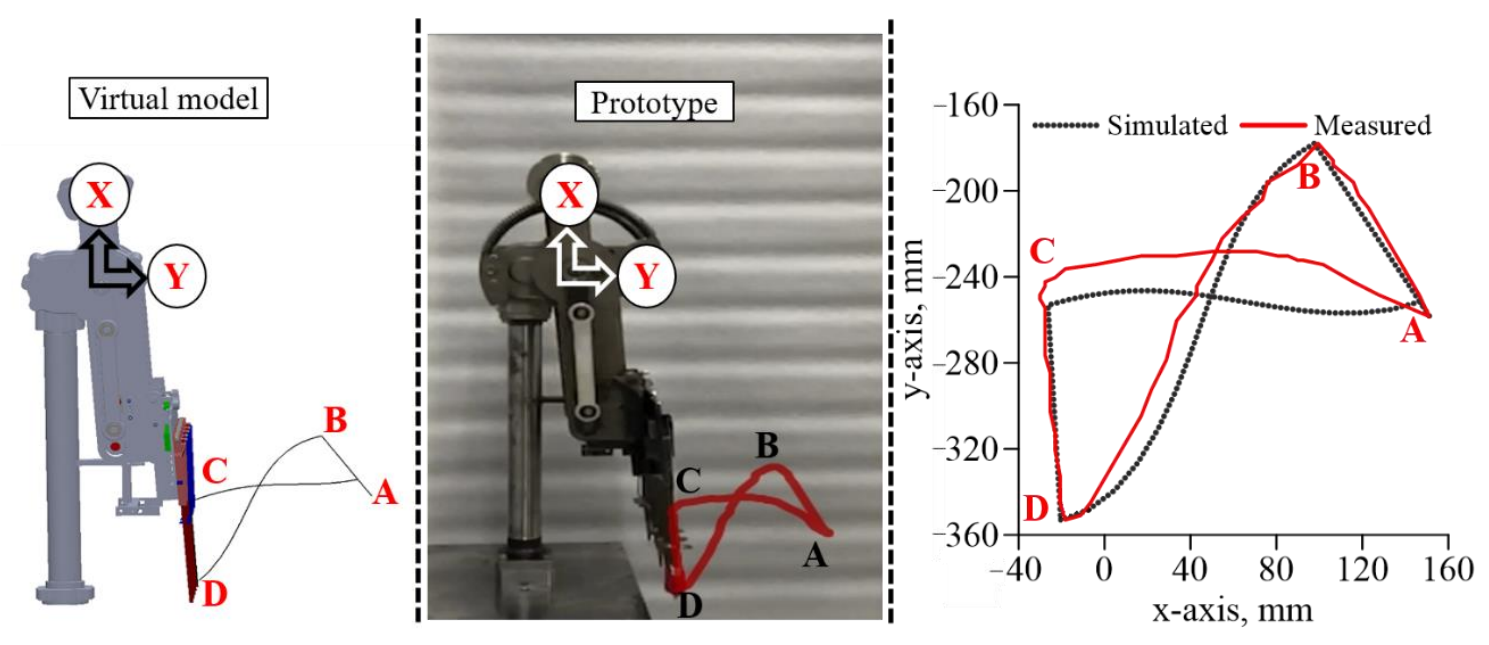

Figure 5. Simulated and measured trajectory curves of the gripper in the $x$ - and $y$-axis directions for one complete picking cycle.

\subsection{Motion Evaluation of the Gripper Using Velocity Analysis}

The velocity of the gripper for different rpm and length combinations is shown in Figure 6. The velocity range of the gripper in the $x$ - and $y$-axes were from 0.40 to $1.10 \mathrm{~m} / \mathrm{s}$ and from 0.50 to $2.20 \mathrm{~m} / \mathrm{s}$, respectively, for gear operating speeds ranging from 30 to $90 \mathrm{rpm}$ (75 to 225 plants/min). 
According to $\mathrm{Hu}$ et al. [29], the gripper's maximum velocity in the $x$ - and $y$-axes were 4.1 and 2.0 $\mathrm{m} / \mathrm{s}$, respectively, for the operation of the $1.08 \mathrm{~s}$ (55 plants $/ \mathrm{min}$ ). Choi et al. [23] simulated a seedling picking mechanism and found velocity levels of 0.40 and $1.40 \mathrm{~m} / \mathrm{s}$ for two-axis gripper movement with a 30 plants/min of seedling transfer capacity, and a success rate of $97 \%$ in seedling pick-up. The gripper velocity is also dependent on the $y$-axis movement (operational height). Han et al. [42] investigated seedling velocity of 1.2 to $2.1 \mathrm{~m} / \mathrm{s}$ for an operational height of 70 to $140 \mathrm{~mm}$. In the manipulator range: $380 \mathrm{~mm}$ and picking stand range: 250 to $350 \mathrm{~mm}$, the gripper was maintained $0.60 \mathrm{~m} / \mathrm{s}$ to $1.23 \mathrm{~m} / \mathrm{s}$ velocity for transferring the seedling at 117 to $118 \mathrm{~mm}$ in $60 \mathrm{rpm}$ operating condition. Based on the velocity analysis, the gripper velocity was lower than the results of previous research. In this study, the picking device was designed as five grippers to transfer the five seedlings simultaneously, and it would reduce the operational time and velocity. This low velocity would transfer the seedling more accurately and safely [42].

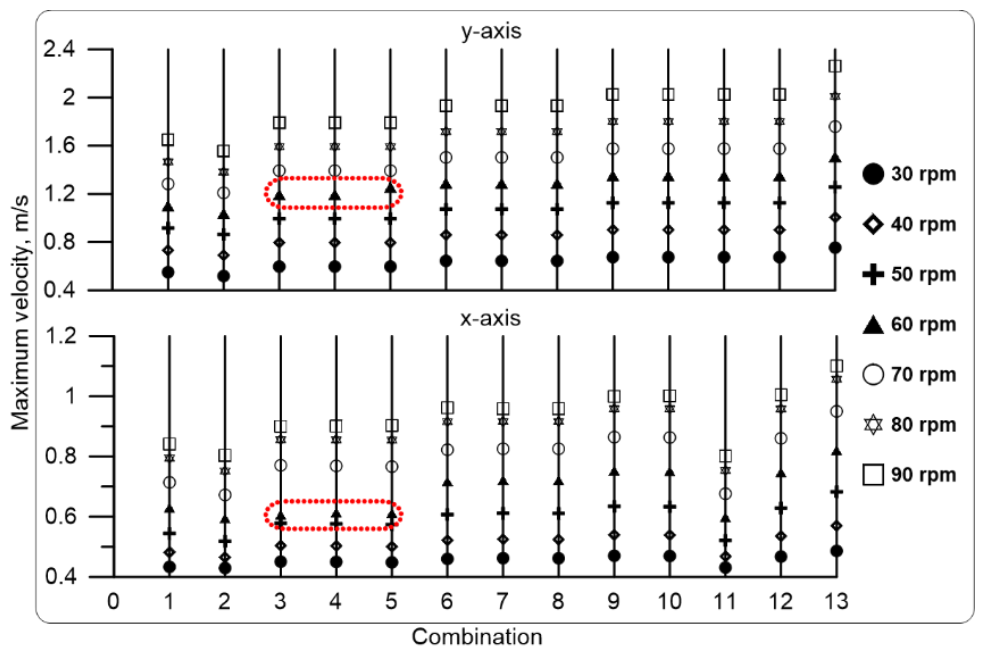

Figure 6. Maximum velocity values of the gripper for different length combinations and operating speeds.

Among the manipulator length $(380 \mathrm{~mm})$ and picking stand length range (250 to $350 \mathrm{~mm}$ ), combination no. 5 (Table 4) was used to validate the gripper velocity. The simulated and measured were conducted at $60 \mathrm{rpm}$, and one complete cycle of picking mechanism (2 s) was performed. Figure 7 shows grippers simulated and measured velocity curves in the $x-, y-$, and $z$-axis directions for one complete picking cycle. The highest velocity for simulation of the $y$ - and $x$-axes were found to be 1.27 and $0.62 \mathrm{~m} / \mathrm{s}$, respectively. During the measurement, the highest velocity for the $y$ and $x$ axes were found to be $1.54 \mathrm{~m} / \mathrm{s}$ and $0.94 \mathrm{~m} / \mathrm{s}$, respectively. There was no velocity in the $z$-axis during simulation owing to the rotational speed of the electric motor of the test bench and the friction of metal in the picking device. This speed and friction of the metal also induced some velocity in the $z$-axis. The highest velocity was $0.13 \mathrm{~m} / \mathrm{s}$ for the $z$-axis. During the simulation and measurement, the velocity levels were statistically the same $(p \leq 0.05)$ for both the axes. The maximum average velocity was recorded as $0.32 \mathrm{~m} / \mathrm{s}$ for the $x$-axis under the measurement condition, whereas the minimum average velocity $(0.18 \mathrm{~m} / \mathrm{s})$ was shown for the $y$-axis in the simulation condition (Table 6$)$. 


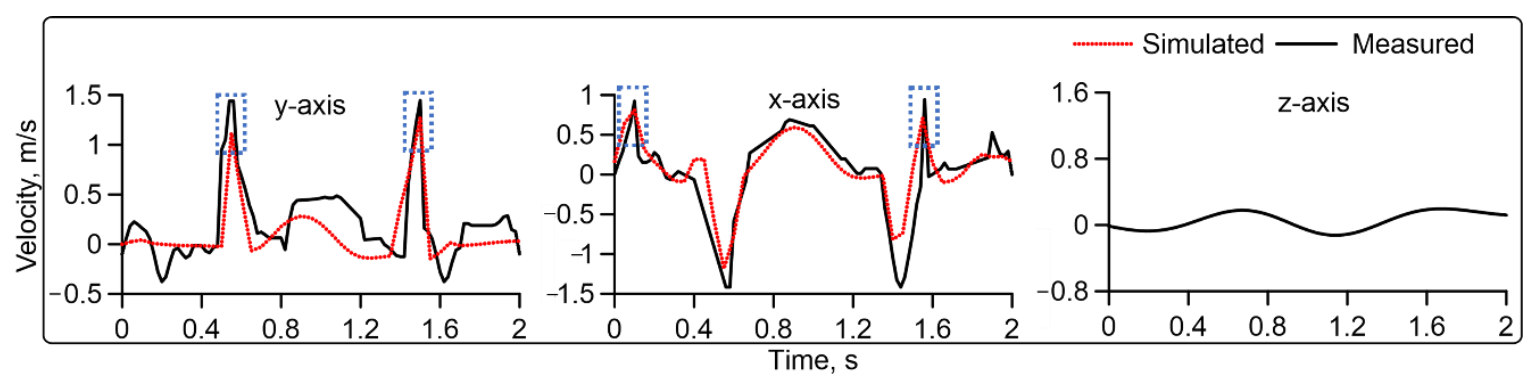

Figure 7. Simulated and measured velocity curves for the gripper in the $x-, y-$, and $z$-axis directions for one complete picking cycle.

Table 6. Comparison of simulated and measured average velocity of the gripper.

\begin{tabular}{ccc}
\hline Axis & Simulated Velocity, $\mathbf{m} / \mathbf{s}$ & Measured Velocity, $\mathbf{m} / \mathbf{s}$ \\
\hline$x$-axis & $0.28 \pm 0.29^{\mathrm{a}}$ & $0.32 \pm 0.34^{\mathrm{a}}$ \\
$y$-axis & $0.18 \pm 0.28^{\mathrm{a}}$ & $0.29 \pm 0.32^{\mathrm{a}}$ \\
\hline
\end{tabular}

a Identified the statistical differences among gripper simulated and measured velocity, according to Tukey's one-way comparisons $(p \leq 0.05)$.

\subsection{Motion Evaluation of the Gripper Using Acceleration Analysis}

The gripper should run in a minimum acceleration range because the seedling is very force sensitive, and high acceleration may induce high force, which may cause root damage or drop the seedling. The allowable gripper acceleration range can maintain safe seedling motion requirements [42]. The gripper acceleration for different length combinations and operating speed conditions are shown in Figure 8. The result shows the acceleration range of the gripper in $y$ and $x$ axes were from 1.33 to $23.74 \mathrm{~m} / \mathrm{s}^{2}$ and from 2.42 to $6.14 \mathrm{~m} / \mathrm{s}^{2}$, respectively. In the manipulator range: $380 \mathrm{~mm}$ and picking stand range: 250 to $350 \mathrm{~mm}$ had comparatively less difference in acceleration between the $x$ and $y$-axis for $60 \mathrm{rpm}$ condition. In this study, pepper seedlings of age 45 days and an average height of $122 \mathrm{~mm}$ were considered for designing the seedling transplantation. Han et al. [42] evaluated a tomato seedling picking device with a plant height ranging from 110 to $130 \mathrm{~mm}$ for 42-day seedlings, and found the maximum acceleration of the gripper in the $x$ - and $y$-axis as 103.80 and $86.90 \mathrm{~m} / \mathrm{s}^{2}$, respectively, and the success ratio in picking up the seedlings as $90 \%$ by analyzing the number of damaged seedlings. Based on the acceleration analysis, the gripper acceleration was lower than the previous research results.

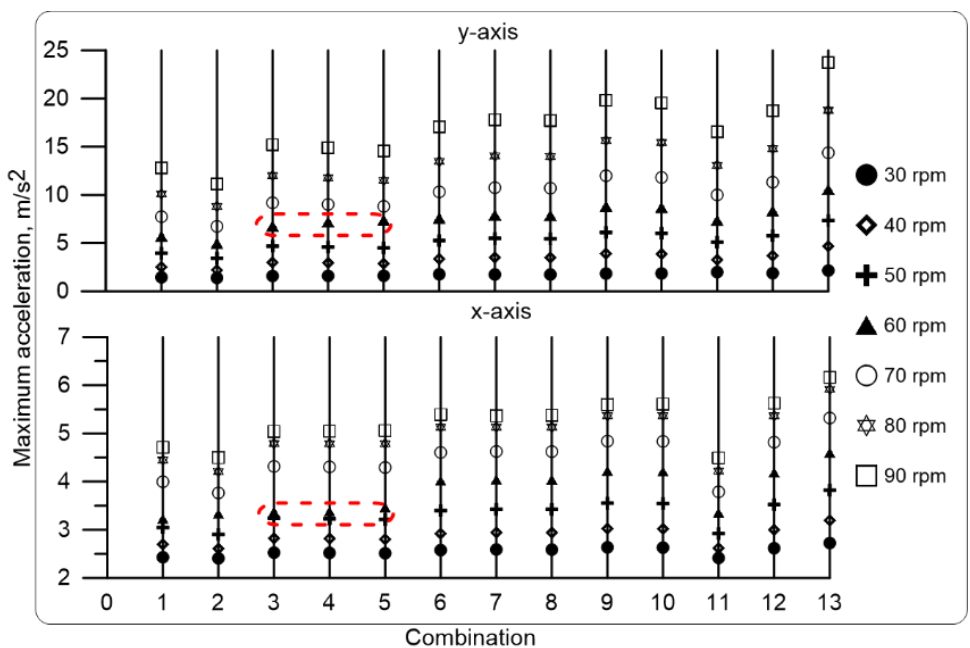

Figure 8. Maximum acceleration of gripper for different length combinations and operating speeds. 
In Figure 9, the simulated and measured acceleration curves of the gripper along the $x-, y$, and $z$-axis directions for one complete picking cycle are depicted. For the simulation and measurement, the operational time was also the same as the velocity analysis. The highest positive acceleration for the simulation of $y$ and $x$ axes were 7.21 and $3.53 \mathrm{~m} / \mathrm{s}^{2}$, respectively. During the measurement, the highest accelerations for the $y$ - and $x$-axes were 8.77 and $5.34 \mathrm{~m} / \mathrm{s}^{2}$, respectively. There was no acceleration in the $z$-axis in the simulation, but the same region of velocity analysis (rotational speed of the motor and the friction of metal) induced some acceleration in the $z$-axis. The highest acceleration for the $z$-axis was $1.12 \mathrm{~m} / \mathrm{s}^{2}$. During the simulation and experiment, the acceleration levels were statistically the same $(p \leq 0.05)$ for the two axes. The maximum average acceleration was recorded as $1.82 \mathrm{~m} / \mathrm{s}^{2}$ for the $x$-axis in the experimental condition, whereas the minimum average velocity $\left(1.03 \mathrm{~m} / \mathrm{s}^{2}\right)$ was shown for the $y$-axis in the simulation condition (Table 7).

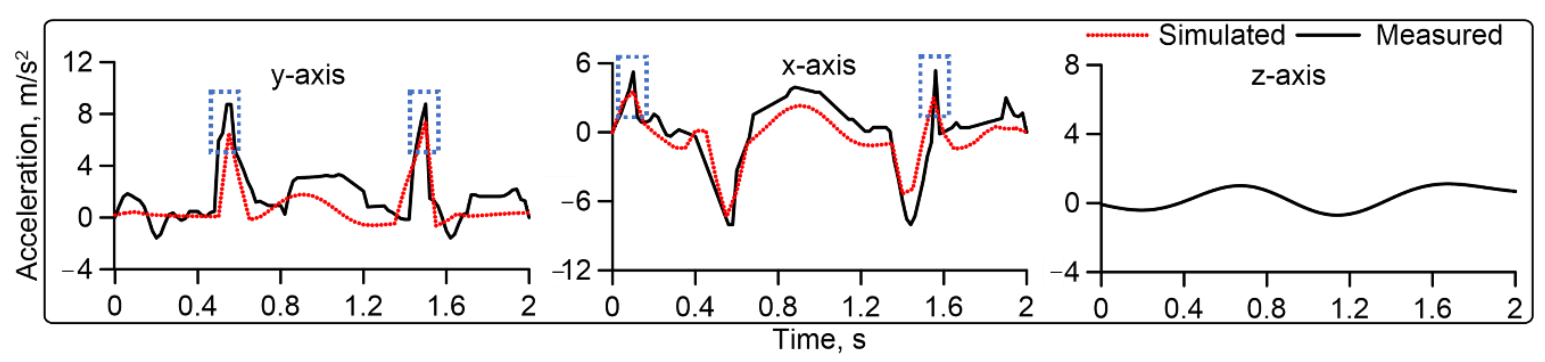

Figure 9. Simulated and measured acceleration curves of the gripper in the $x-, y-$, and $z$-axis directions for one complete picking cycle.

Table 7. Comparison of simulated and measured average acceleration of the gripper.

\begin{tabular}{ccc}
\hline Axis & Simulated Acceleration, $\mathbf{m} / \mathbf{s}^{\mathbf{2}}$ & Measured Acceleration, $\mathbf{m} / \mathbf{s}^{\mathbf{2}}$ \\
\hline$x$-axis & $1.60 \pm 1.68^{\mathrm{a}}$ & $1.82 \pm 1.96^{\mathrm{a}}$ \\
$y$-axis & $1.03 \pm 1.60^{\mathrm{a}}$ & $1.68 \pm 1.86^{\mathrm{a}}$ \\
\hline
\end{tabular}

a Identified statistical differences among gripper simulated and measured acceleration, according to Tukey's one-way comparisons $(p \leq 0.05)$.

The power consumption of the picking device depends on the acceleration of the grippers. The simulation and measurement were conducted at $60 \mathrm{rpm}$ to check the power consumption. Figure 10 shows the power consumption of the picking mechanism. The required power level of the picking device for simulated and measured was found to be $16.14 \mathrm{~W}$ and $18.59 \mathrm{~W}$, respectively.

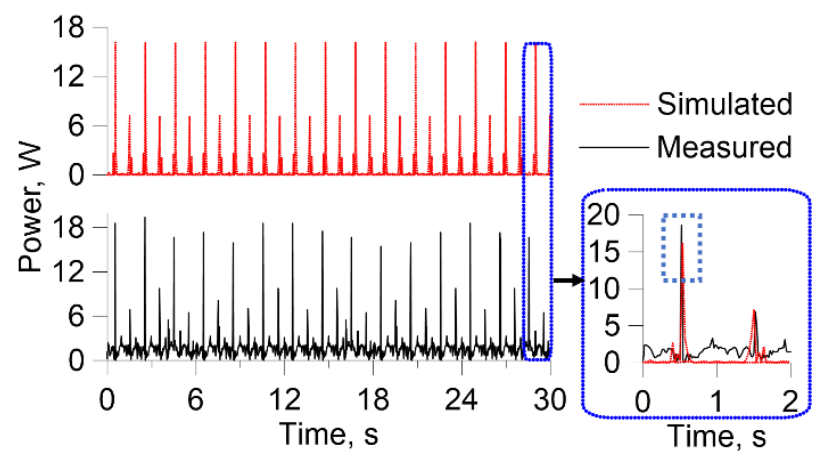

Figure 10. Simulated and measured power consumption of the picking device at $60 \mathrm{rpm}$ condition.

In addition, the experiment with a prototype was carried out for speeds ranging from 30 to $90 \mathrm{rpm}$ at $10 \mathrm{rpm}$ intervals to check the power consumption for the different conditions. Figure 11 shows the power consumption of the picking device under different speed conditions. The measured power on the picking device showed regular fluctuation patterns during the operation. The power at $30 \mathrm{rpm}$ 
was approximately five times lower than that at $90 \mathrm{rpm}$. The average power consumption on the picking device of $30,40,50,60,70,80$, and $90 \mathrm{rpm}$ were $0.30,0.80,1.08,1.80,1.27,2.73$, and $2.48 \mathrm{~W}$, respectively. Therefore, the power consumption on the picking device increased when the speed of the device increased. Table 8 shows the average power consumption for all the speed conditions. According to Table 8, the power of the picking device was significantly different $(p \leq 0.05)$. The speed conditions were divided into three levels: low (30 and $40 \mathrm{rpm})$, middle $(50,60$, and $70 \mathrm{rpm})$, and high (80 and $90 \mathrm{rpm}$ ) to describe the significant differences. Here, no statistical difference was observed between the speeds of at one level, but significant differences were observed between the other levels. The power is directly proportional to acceleration, and the result indicates that, for $10 \mathrm{rpm}$ increments, the acceleration must be increased by, on an average, $66 \pm 1.23 \% \mathrm{~m} / \mathrm{s}^{2}$.

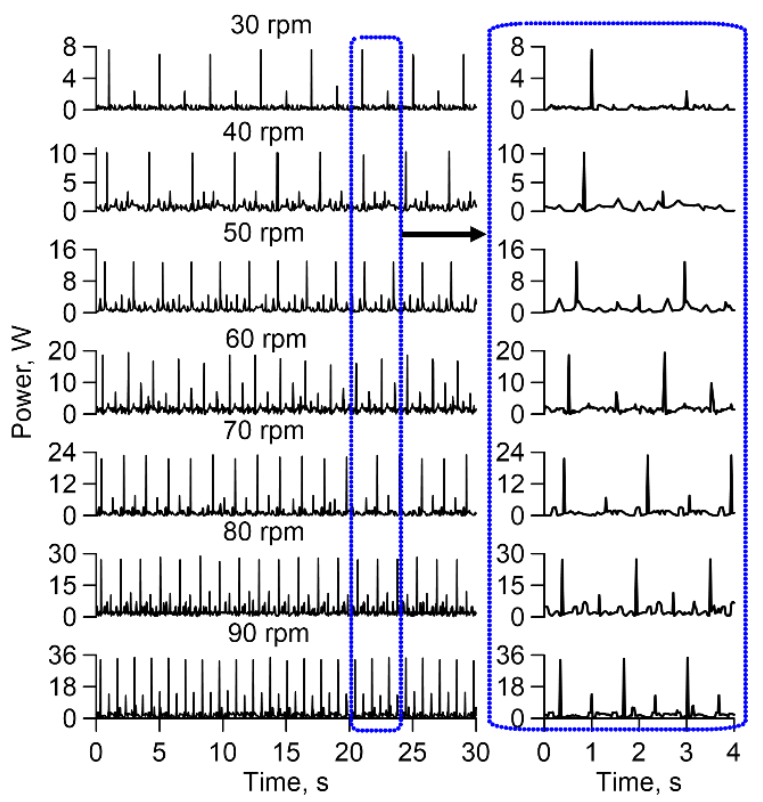

Figure 11. Power consumption of the picking device in different speed conditions.

Table 8. Results of power consumption according to speed condition.

\begin{tabular}{cccccccc}
\hline \multirow{2}{*}{ Parameter } & \multicolumn{7}{c}{ Power Requirement, $\mathbf{~}$} \\
\cline { 2 - 8 } & $\mathbf{3 0} \mathbf{~ r p m}$ & $\mathbf{4 0} \mathbf{~ r p m}$ & $\mathbf{5 0} \mathbf{~ r p m}$ & $\mathbf{6 0} \mathbf{~ r p m}$ & $\mathbf{7 0 ~} \mathbf{~ p m}$ & $\mathbf{8 0} \mathbf{~ r p m}$ & $\mathbf{9 0} \mathbf{~ r p m}$ \\
\hline Min. & 0.01 & 0.01 & 0.19 & 0.20 & 0.21 & 0.25 & 0.29 \\
Avg. & $0.30 \pm 0.63^{\mathrm{a}}$ & $0.80 \pm 0.92^{\mathrm{a}}$ & $1.08 \pm 1.33^{\mathrm{b}}$ & $1.80 \pm 2.06^{\mathrm{b}}$ & $1.27 \pm 2.43^{\mathrm{b}}$ & $2.73 \pm 3.32^{\mathrm{c}}$ & $2.48 \pm 4.31^{\mathrm{c}}$ \\
Max. & 7.59 & 10.41 & 13.06 & 19.38 & 22.91 & 28.70 & 34.42 \\
\hline a,b,c Identified the statistical differences among different speed conditions according to Tukey's one-way \\
\multicolumn{7}{l}{ comparisons $(p \leq 0.05)$. }
\end{tabular}

\section{Conclusions}

In this study, a set of suitable manipulator and picking stand dimensions were evaluated according to the workspace of the picking operation and azimuth angle of the seedling tray. The picking device under development was designed to enable the grippers for extracting the pepper seedlings from the azimuth $90^{\circ}$ seedling tray and transferred them onto a conveying device. In order to obtain the results of the kinematic analysis, the gripper position, velocity, and acceleration were affected by the different dimensions of the picking device. In addition, the connecting rod position ( $L_{3}$ bar), reflecting factor $(\delta)$, and gripper movement $(\Delta \theta)$ were taken into consideration when designing the dimensions. The simulation and experimental results indicated that the developed picking device can transfer five seedlings at a time under a $60 \mathrm{rpm}$ (150 plants/min) operating condition with minimum velocity and acceleration. This low velocity and acceleration could contribute to a more successful picking operation by decreasing pepper seedling damage. In the field test, $18.59 \mathrm{~W}$ power was required 
for operating the picking mechanism of a low-powered automatic pepper transplanter. The outcomes of this study provide the guidelines for developing a small-scale automatic transplanting mechanism to achieve more accurate pepper seedling transplantation.

Author Contributions: Conceptualization, S.-O.C. and M.N.I.; Methodology, S.-O.C.; Software, M.N.I.; Validation, M.N.I., S.-O.C., Y.-J.K., and T.P.; Formal analysis, M.N.I., M.Z.I., and M.A.; Investigation, S.-O.C., T.P., and M.S.N.K.; Resources, S.-O.C.; Data curation, M.N.I., M.Z.I., and M.S.N.K.; Writing-original draft preparation, M.N.I.; Writing-review and editing, S.-O.C., Y.-J.K., T.P., and M.C.; Visualization, M.N.I., M.Z.I., and M.C.; Supervision, S.-O.C.; Project administration, S.-O.C.; Funding acquisition, S.-O.C. All authors have read and agreed to the published version of the manuscript.

Funding: This research was supported by the Korea Institute of Planning and Evaluation for Technology in Food, Agriculture, Forestry and Fisheries (IPET), through the Advanced Production Technology Development Program, funded by the Ministry of Agriculture, Food and Rural Affairs (MAFRA) (grant no. 317013-03), Republic of Korea.

Conflicts of Interest: The authors declare that they have no conflict of interest.

\section{References}

1. Bosland, P.W.; Votava, E.J. Peppers: Vegetable and Spice Capsicums, 2nd ed.; CABI: New York, NY, USA, 2000; pp. 6-9.

2. Maia, A.A.D.; de Morais, L.C. Kinetic parameters of red pepper waste as biomass to solid biofuel. Bioresour. Technol. 2016, 204, 157-163. [CrossRef] [PubMed]

3. Mancinelli, R.; Muleo, R.; Marinari, S.; Radicetti, E. How soil ecological intensification by means of cover crops affects nitrogen use efficiency in pepper cultivation. Agriculture 2019, 9, 145. [CrossRef]

4. FAO (Food and Agriculture Organization of the United Nations). 2020. Available online: http://www.fao. org/faostat/en/\#data/QC (accessed on 27 October 2020).

5. Aziz, N.S.; Sofian-Seng, N.; Mohd Razali, N.S.; Lim, S.J.; Mustapha, W.A. A review on conventional and biotechnological approaches in white pepper production. J. Sci. Food Agric. 2019, 99, 2665-2676. [CrossRef] [PubMed]

6. Siddique, M.A.A.; Kim, W.S.; Kim, Y.S.; Kim, T.J.; Choi, C.H.; Lee, H.J.; Chung, S.O.; Kim, Y.J. Effects of temperatures and viscosity of the hydraulic oils on the proportional valve for a rice transplanter based on PID control algorithm. Agriculture 2020, 10, 73. [CrossRef]

7. Park, S.H.; Kim, J.Y.; Choi, D.K.; Kim, C.K.; Kwak, T.Y.; Cho, S.C. Development of walking type Chinese cabbage transplanter. J. Biosyst. Eng. 2005, 30, 81-88. [CrossRef]

8. Islam, M.N.; Iqbal, M.Z.; Kabir, M.S.N.; Jung, K.Y.; Mun, D.H.; Chung, S.O. Performance evaluation of trenchless subsurface drainage piping machine. J. Biosyst. Eng. 2019, 44, 218-225. [CrossRef]

9. Jin, X.; Cheng, Q.; Zhao, B.; Ji, J.; Li, M. Design and test of 2ZYM-2 potted vegetable seedlings transplanting machine. Int. J. Agric. Biol. Eng. 2020, 13, 101-110. [CrossRef]

10. Ji, J.; Sun, J.; Jin, X.; Li, M.; Du, X. Development of a PVDF sensor for potted seedling clamping force of vegetable transplanting. Int. J. Agric. Biol. Eng. 2019, 12, 111-118. [CrossRef]

11. Kumar, G.V.P.; Raheman, H. Vegetable transplanters for use in developing countries-A review. Int. J. Veg. Sci. 2008, 14, 232-255. [CrossRef]

12. Tsuga, K. Development of fully automatic vegetable transplanter. Jpn. Agric. Res. Q. 2000, 34, 21-28.

13. Rahul, K.; Raheman, H.; Paradkar, V. Design and development of a 5R 2DOF parallel robot arm for handling paper pot seedlings in a vegetable transplanter. Comput. Electron. Agric. 2019, 166, 105014. [CrossRef]

14. Gu, Y.; Li, Z.; Zhang, Z.; Li, J.; Chen, L. Path tracking control of field information-collecting robot based on improved convolutional neural network algorithm. Sensors 2020, 20, 797. [CrossRef] [PubMed]

15. Jin, X.; Li, D.; Ma, H.; Ji, J.; Zhao, K.; Pang, J. Development of single row automatic transplanting device for potted vegetable seedlings. Int. J. Agric. Biol. Eng. 2018, 11, 67-75. [CrossRef]

16. Ramin Shamshiri, R.; Weltzien, C.; Hameed, I.A.; J Yule, I.; E Grift, T.; Balasundram, S.K.; Pitonakova, L.; Ahmad, D.; Chowdhary, G. Research and development in agricultural robotics: A perspective of digital farming. Int. J. Agric. Biol. Eng. 2018, 11, 1-11. [CrossRef]

17. Han, L.; Mao, H.; Kumi, F.; Hu, J. Development of a multi-task robotic transplanting workcell for greenhouse seedlings. Appl. Eng. Agric. 2018, 34, 335-342. [CrossRef]

18. Hwang, H.; Sistler, F.E. A robotic pepper transplanter. Appl. Eng. Agric. 1986, 2, 2-5. [CrossRef] 
19. Simonton, W. Robotic end effector for handling greenhouse plant material. Trans. ASAE 1991, 34, $2615-2621$. [CrossRef]

20. Ting, K.C.; Giacomelli, G.A.; Shen, S.J. Robot workcell for transplanting of seedlings. Part I. Layout and materials flow. Trans. ASAE 1990, 33, 1005-1010. [CrossRef]

21. Yang, Y.; Ting, K.C.; Giacomelli, G.A. Factors affecting performance of sliding-needles gripper during robotic transplanting of seedlings. Appl. Eng. Agric. 1991, 7, 493-498. [CrossRef]

22. Ryu, K.H.; Kim, G.; Han, J.S. AE-Automation and emerging technologies: Development of a robotic transplanter for bedding plants. J. Agric. Eng. Res. 2001, 78, 141-146. [CrossRef]

23. Choi, W.C.; Kim, D.C.; Ryu, I.H.; Kim, K.U. Development of a seedling pick-up device for vegetable transplanters. Trans. ASAE 2002, 45, 13. [CrossRef]

24. Gao, G.H.; Feng, T.X.; Yang, H.; Li, F. Development and optimization of end-effector for extraction of potted anthurium seedlings during transplanting. Appl. Eng. Agric. 2016, 32, 37-46. [CrossRef]

25. Sun, L.; Mao, S.; Zhao, Y.; Liu, X.; Zhang, G.; Du, X. Kinematic analysis of rotary transplanting mechanism for wide-narrow row pot seedlings. Trans. ASAE 2016, 59, 475-485. [CrossRef]

26. Bingliang, Y.; Weiming, Y.; Gaohong, Y.; Yang, G.; Xiong, Z. Optimization design and test of rice plug seedling transplanting mechanism of planetary gear train with incomplete eccentric circular gear and non-circular gears. Int. J. Agric. Biol. Eng. 2017, 10, 43-55. [CrossRef]

27. Yin, D.Q.; Wang, J.W.; Zhao, Y. Automatic corn potted-seedling transplanter of cycloid gear trains. Appl. Mech. Mater. 2014, 530-531, 960-966. [CrossRef]

28. Mao, H.; Han, L.; Hu, J.; Kumi, F. Development of a pincette-type pick-up device for automatic transplanting of greenhouse seedlings. Appl. Eng. Agric. 2014, 30, 547-556. [CrossRef]

29. Hu, J.; Yan, X.; Ma, J.; Qi, C.; Francis, K.; Mao, H. Dimensional synthesis and kinematics simulation of a high-speed plug seedling transplanting robot. Comput. Electron. Agric. 2014, 107, 64-72. [CrossRef]

30. Jiang, Z.; Hu, Y.; Jiang, H.; Tong, J. Design and force analysis of end-effector for plug seedling transplanter. PLoS ONE 2017, 12, e0180229. [CrossRef]

31. Seo, T.C.; An, S.W.; Kim, S.M.; Nam, C.W.; Chun, H.; Kim, Y.C.; Kang, T.K.; Sung Woo, K.; Jeon, S.G.; Jang, K.S. Effect of the seedlings difference in cylindrical paper pot trays on initial root growth and yield of pepper. Prot. Hortic. Plant Fact. 2017, 26, 368-377. [CrossRef]

32. Dihingia, P.C.; Prasanna Kumar, G.V.; Sarma, P.K. Development of a hopper-type planting device for a walk-behind hand-tractor-powered vegetable transplanter. J. Biosyst. Eng. 2016, 41, 21-33. [CrossRef]

33. Ali, M.; Lee, Y.S.; Kabir, M.S.N.; Kang, T.K.; Lee, S.H.; Chung, S.O. Kinematic analysis for design of the transportation part of a tractor-mounted chinese cabbage collector. J. Biosyst. Eng. 2019, 44, 226-235. [CrossRef]

34. Li, Y.; Xu, Q. Kinematic analysis of a 3-PRS parallel manipulator. Robot. Comput. Integr. Manuf. 2007, 23, 395-408. [CrossRef]

35. Zhao, X.; Cui, H.; Dai, L.; Chen, J.; Ye, B. Kinematic analysis and experimental research on the seedling pick-up mechanism of a second-order free noncircular planetary gear system. Appl. Eng. Agric. 2017, 33, 169-179. [CrossRef]

36. Akbari, S.; Fallahi, F.; Pirbodaghi, T. Dynamic analysis and controller design for a slider-crank mechanism with piezoelectric actuators. J. Comput. Des. Eng. 2016, 3, 312-321. [CrossRef]

37. Ha, J.L.; Fung, R.F.; Chen, K.Y.; Hsien, S.C. Dynamic modeling and identification of a slider-crank mechanism. J. Sound Vib. 2006, 289, 1019-1044. [CrossRef]

38. Islam, N. Structural Analysis of a Clamp-Type Picking Mechanism for a $2.7 \mathrm{~kW}$ Automatic Pepper Transplanter. Master's Thesis, Chungnam National University, Daejeon, Korea, 2020.

39. Iqbal, M.Z. Design of a Gear Driven Hopper Type Dibbling Mechanism for a $2.7 \mathrm{~kW}$ Two-Row Pepper Transplanter. Master's Thesis, Chungnam National University, Daejeon, Korea, 2019.

40. Conti, R.; Meli, E.; Ridolfi, A. A novel kinematic architecture for portable hand exoskeletons. Mechatronics 2016, 35, 192-207. [CrossRef]

41. Puig-Diví, A.; Escalona-Marfil, C.; Padullés-Riu, J.M.; Busquets, A.; Padullés-Chando, X.; Marcos-Ruiz, D. Validity and reliability of the Kinovea program in obtaining angles and distances using coordinates in 4 perspectives. PLoS ONE 2019, 14, e0216448. [CrossRef]

42. Han, L.; Mao, H.; Hu, J.; Tian, K. Development of a doorframe-typed swinging seedling pick-up device for automatic field transplantation. Span. J. Agric. Res. 2015, 13, e0210. [CrossRef] 
43. Korayem, M.H.; Rahimi, H.N.; Nikoobin, A. Mathematical modeling and trajectory planning of mobile manipulators with flexible links and joints. Appl. Math. Model. 2012, 36, 3229-3244. [CrossRef]

Publisher's Note: MDPI stays neutral with regard to jurisdictional claims in published maps and institutional affiliations.

(C) 2020 by the authors. Licensee MDPI, Basel, Switzerland. This article is an open access article distributed under the terms and conditions of the Creative Commons Attribution (CC BY) license (http://creativecommons.org/licenses/by/4.0/). 